\title{
Bone Handles and Pottery
}

\author{
By Allan J. Hudson
}

$\mathbf{T}$ HE FULL SERIES in the deepest excavations in the Besant (Sandy Creek) valley is, first, the modern sod, approximately a foot in depth; second, a drift sand zone varying considerably in depth; third, the black earth horizon or zone averaging at least fifteen inches in depth; and lastly, a light colored zone probably derived from the original river bank by washing or slumping and resting directly on a level river sand bed.

At Hearth 2, where I have worked the last two summers, the light colored zone has not shown up as yet. The black earth rests directly on the floor which is sterile.

Within the modern sod, about six to eight inches below the surface is a distinct bone layer and it is in this bone layer that socketed bone handles occur, and only there so far. They have been made by cutting a groove all round a rib bone and breaking in two. We find both the used handles and the rejects. Very rarely one side of the bone handle is decorated with criss-cross diagonal scratch marks evenly spaced; more often the edges have notches cut in them, sometimes continuously and sometimes in paired groups. What they were used for is a problem. We have never found one in direct combination with any stone artifact. It is usually thought that scrapers were fitted into them but unfortunately for the idea, there are no scrapers to go with them-the common type scrapers are quite unsuitable. Perhaps the problem illustrates the limitations of surface collecting. In the black earth zone a rare scraper or shouldered knife may be found that can be fitted into the socket but excavation work shows that there may be as much as a thousand years between the periods, though one would not know that by relying on surface collecting for evidence.

I have seen it suggested that they could be used to hold points in order to grind, and a careful cleaning out of two I found recenty show that the socket is suitable for the purpose. The older points found in the black earth layer are too big and thick, but some later points, somewhat slimmer and narrower would fit admirably. Some triangular forms which may be knives or scrapers rather than projectile points could be used with bone handles, but whether the proper correlation can be shown, I am not prepared to say at present.

Further to the appearance of pottery in this area the black earth zone contains two distinct bone layers, the lower one, about eight inches above the river sand floor, being the heaviest. In June of this year, pottery with a wrinkled outer surface has shown up in this lower bone layer. But in July I obtained several pieces-some of the rim pieces fitted together-in the bottom six inches of black earth. It is quite plain and somewhat crumbly, being made of poor material. There is an interesting question regarding Indian pottery. Only a few miles from the site are exposures or the face of the Missouri Coteau of true pottery clay, but the Indians do not seem to have used the material. In view of the tremendous exposures of pottery clay in southern Saskatchewan, did the Indians make effective use of the material Nature so generously provided?

\section{Starlings}

H. M. Rayner, Ituna

NOTE on browsing through the Jan.-Feb.-Mar. BLUE JAY, that a lady who lives in the Qu'Appelle Valley mentions the European Starling and asks if they are becoming more frequent visitors or habitues of the prairie west.
I noted them for the first time at Ituna, this spring. It was in early May. A small flock of about eight or ten birds were seen in the garden, feeding on garbage accumulated during the winter and uncovered by the melting snow. I have not seen any since, but I take this for a sign that they are getting established in the province. 